\title{
Clinicopathologic Study of Chromosomal Aberrations in Gastric Lymphomas of Korean Patients
}

\author{
Wook Youn $\mathrm{Kim}^{1} \cdot$ Jung-Ho Kim \\ Hyoungsuk $\mathrm{Ko}^{1}$. Young A Kim${ }^{2}$ \\ Yoon Kyung Jeon ${ }^{1} \cdot$ Chul-Woo Kim ${ }^{1}$ \\ 'Department of Pathology, Seoul \\ National University College of \\ Medicine, ${ }^{2}$ Department of Pathology, \\ Seoul National University Boramae \\ Hospital, Seoul, Korea \\ Received : September 19, 2008 \\ Accepted : October 27, 2008 \\ Corresponding Author \\ Young A Kim, M.D. \\ Department of Pathology, Seoul National University \\ Boramae Hospital, Shindaebang 2-dong, Dongjak-gu, \\ Seoul 156-707, Korea \\ Tel: 02-870-2643 \\ Fax: 02-831-0261 \\ E-mail: pathgirl@paran.com
}

\begin{abstract}
Background : The incidence and clinical correlation of $M A L T 1$ translocation and numerical aberrations in Korean gastric MALT lymphoma patients have been rarely reported. We studied the incidence and clinicopathologic relationship of these chromosomal aberrations in Korean gastric lymphomas. Methods : Seventy-six gastric lymphomas, which consisted of 40 low grade MALT lymphoma, 4 high grade MALT lymphoma and 32 diffuse large B-cell lymphoma (DLBCL) cases, were analyzed for the detection of $\mathrm{t}(11 ; 18)$ API2-MALT1, $\mathrm{t}(14 ; 18) \operatorname{lgH}-M A L T 1$ and aneuploidies of chromosomes 3 or 18 using fluorescence in situ hybridization. Results : The t $(11 ; 18)$ was demonstrated in 3 low grade MALT lymphomas (7.5\%) and one DLBCL, which was associated with advanced stage, deeper invasion, and disease progression or relapse. The $t(14 ; 18)$ was demonstrated in none of these cases. Trisomy 3 and 18 were detected in $8(11 \%)$ and 11 of 76 cases (12.5\%) respectively, and found only in translocation-negative cases. Two of 4 high grade MALT lymphomas showed trisomy 18. All patients survived with successful second treatment after progression or relapse. Conclusions : The $t(11 ; 18) A P I 2-M A L T 1$ was not quite frequent in Korean low grade gastric MALT lymphomas and was associated with advanced clinical situations. Overall prognosis was good for long-term follow-up regardless of progression or relapse.
\end{abstract}

Key Words : Lymphoma, B-cell, marginal zone; Translocation, genetic; API2-MALT1 fusion protein, human; Trisomy
Gastric extranodal marginal zone B-cell lymphoma of mucosaassociated lymphoid tissue (MALT lymphoma) is a unique entity in that pathogenetic role of a microbial agent, Helicobacter pylori (H. pylori) is well established. ${ }^{1}$ Chronic antigenic stimulation by $H$. pylori causes proliferation of lymphoid tissue that is originally absent in normal gastric mucosa, and furthermore promotes the development of low grade malignant lymphoma by acquisition of genetic aberrations such as balanced translocations. The known balanced translocations in MALT lymphomas include $\mathrm{t}(11 ; 18)$ (q21;q21) API2-MALT1, t(14;18)(q32;q21) IgH-MALT1, t(1; 14)(p22;q32) BCL10-IgH, and t(3;14)(p14.1; q32) FOXP1-IgH. ${ }^{2}$ Among these four types of translocation, $\mathrm{t}(11 ; 18)(\mathrm{q} 21 ; \mathrm{q} 21)$ harboring API2-MALT1 fusion is the most common chromosomal aberration reported in gastric MALT lymphoma. ${ }^{3}$

There have been various studies about the incidence of translocation in gastric MALT lymphoma, which were described mainly from Western and Japanese countries. According to the published data, $\mathrm{t}(11 ; 18)$ translocation was found in $5-48 \%$ of the cases in previous studies. ${ }^{4-16}$ In a recent collective study, Remstein et al. suggested geographic variation might be present in the incidence of translocation in gastric MALT lymphoma, comparing the published data about the incidence of translocation between Europe, Japan and North America. ${ }^{15}$ In contrast, there was a new, conflicting report that no significant regional difference was observed in a large, Japanese population-based study. ${ }^{16}$ To date, the incidence of translocation involving MALT1 in gastric MALT lymphoma has not been studied in Korean populations in spite of the high prevalence of gastric MALT lymphoma compared to Western countries.

The clinicopathologic relationship between $\mathrm{t}(11 ; 18)$ API2MALT1 and gastric MALT lymphoma has been analyzed in several previous reports, suggesting that translocation-positive groups are associated with $H$. pylori eradication failure, local aggressiveness and advanced clinical stage. ${ }^{10,17}$ In respect to translocationnegative group, occupying majority of gastric MALT lymphoma, instead, other chromosomal aberrations such as numerical aberrations of chromosomes 3,12, and 18 were observed frequently., 718 It was revealed that numerical aberrations and API2-MALT1 translocation were detected in mutually exclusive fashion using 
fluorescence in situ hybridization (FISH), which implied different biologic aspects in relation to pathogenesis. ${ }^{4}$ Furthermore, numerical aberrations were often demonstrated in high grade MALT lymphoma with accompanying DLBCL component, which was rarely associated with API2-MALT1 translocation. ${ }^{2}$ The clinicopathologic significance of numerical aberrations has not been well known compared to API2-MALT1 translocation, although there were a few reports showing that trisomy 3-positive cases are associated with resistance to eradication, ${ }^{19}$ or extracopies of MALT1, suggestive of partial or complete trisomies 18 , predicts worse clinical behavior. ${ }^{16}$

Another translocation involving MALT1, t(14;18)(q32;q21) IGH-MALT1, which is frequent in pulmonary or ocular type MALT lymphomas, are rarely observed in gastric MALT lymphomas. ${ }^{2.20}$ The clinicopathologic relationship of this translocation in gastric MALT lymphoma was not well known. ${ }^{2,20}$

To clarify these issues, we studied the incidence of chromosomal aberrations involving MALT1 and numerical aberrations of chromosomes 3 or 18, and analyzed the clinicopathologic relationship of these chromosomal aberrations using FISH in a series of gastric lymphomas of Korean population, including high grade MALT lymphomas and DLBCLs.

\section{MATERIALS AND METHODS}

\section{Materials}

We collected 76 formalin-fixed, paraffin embedded tissues of primary gastric lymphomas which consisted of 62 surgically resected and 14 endoscopically biopsied specimens at Seoul National University Hospital from 1992 to 2004. These cases were reviewed and reconfirmed by pathologists, by the criteria of the World Health Organization classification of tumors of hematopoietic and lymphoid tissues. ${ }^{21}$ The tumors were classified according to the histological grades proposed by Isaacson. ${ }^{22}$ Seventy-six primary gastric lymphoma cases consisted of 40 MALT lymphomas (low grade MALT lymphoma), 4 DLBCLs with MALT lymphoma (high grade MALT lymphoma) and 32 DLBCLs without MALT lymphoma. All fourteen endoscopic biopsies were low grade MALT lymphomas. Depth of invasion and regional lymph node involvement were determined by histological examination of resected specimen or by clinical staging work-up using endoscopic ultrasonography or CT scan for biopsy specimen unavailable for it. $H$. pylori infection status was evaluated by microscopic examination of specimen.
The relevant clinical information was taken from the medical records (Table 1). Clinical stage was classified according to the modified Ann Arbor system for primary gastric lymphoma. Twelve low grade MALT lymphoma patients were treated by $H$. pylori eradication. Complete remission was defined as no clinical evidence of disease and complete absence of histological evidence in follow-up biopsy specimens. Two patients received second-line treatment such as chemoradiothreapy $(\mathrm{n}=1)$ or gastrectomy $(\mathrm{n}=1)$ due to progression or relapse after eradication therapy. Twentysix cases were initially treated by gastrectomy. After gastrectomy, three patients received adjuvant radiotherapy $(\mathrm{n}=1)$ or chemotherapy $(\mathrm{n}=2)$. No clinical information was available in 2 cases.

Table 1. Clinical characteristics in 76 primary gastric lymphoma patients

\begin{tabular}{|c|c|c|c|}
\hline Characteristics & $\mathrm{ML}$ & $\mathrm{ML}+\mathrm{DLBCL}$ & DLBCL \\
\hline \multicolumn{4}{|l|}{ Age } \\
\hline$\leq 60$ years & $34(85 \%)$ & $3(75 \%)$ & $17(53 \%)$ \\
\hline$>60$ years & $6(15 \%)$ & $1(25 \%)$ & $15(47 \%)$ \\
\hline \multicolumn{4}{|l|}{ Sex } \\
\hline Male & $19(47 \%)$ & $1(25 \%)$ & $21(66 \%)$ \\
\hline Female & $21(53 \%)$ & $3(75 \%)$ & $11(34 \%)$ \\
\hline \multicolumn{4}{|l|}{ Depth of invasion } \\
\hline Superficiala $^{a}$ & $19(67 \%)$ & $1(25 \%)$ & $5(17 \%)$ \\
\hline Deep $^{b}$ & $11(33 \%)$ & $3(75 \%)$ & $24(83 \%)$ \\
\hline \multicolumn{4}{|l|}{ Clinical stage } \\
\hline 1 & 35 (88\%) & $4(100 \%)$ & $5(36 \%)$ \\
\hline$\|$ & $3(7 \%)$ & $0(0 \%)$ & $7(50 \%)$ \\
\hline III & $0(0 \%)$ & $0(0 \%)$ & $1(7 \%)$ \\
\hline IV & $2(5 \%)$ & $0(0 \%)$ & $1(7 \%)$ \\
\hline \multicolumn{4}{|l|}{ H. pylori status } \\
\hline Positive & $14(42 \%)$ & $1(33 \%)$ & $10(40 \%)$ \\
\hline Negative & $19(58 \%)$ & $2(67 \%)$ & $15(60 \%)$ \\
\hline \multicolumn{4}{|l|}{ Response to eradication } \\
\hline Complete remission (CR) & $2(16.7 \%)$ & NA & NA \\
\hline Non-CR & $10(83.3 \%)$ & NA & NA \\
\hline \multicolumn{4}{|l|}{ Bone marrow involvement } \\
\hline Yes & $3(19 \%)$ & $0(0 \%)$ & NA \\
\hline No & $13(82 \%)$ & $4(100 \%)$ & NA \\
\hline \multicolumn{4}{|l|}{ Lymph node involvement } \\
\hline Positive & $6(16 \%)$ & $1(25 \%)$ & $21(66 \%)$ \\
\hline Negative & $32(84 \%)$ & $3(75 \%)$ & $11(34 \%)$ \\
\hline \multicolumn{4}{|l|}{ Progression or relapse } \\
\hline Yes & $3(9 \%)$ & $0(0 \%)$ & $4(27 \%)$ \\
\hline No & $30(91 \%)$ & $4(100 \%)$ & $11(73 \%)$ \\
\hline \multicolumn{4}{|l|}{ Survival } \\
\hline Death & $0(0 \%)$ & $0(0 \%)$ & $14(43.8 \%)$ \\
\hline Survival rate & $40(100 \%)$ & $4(100 \%)$ & 18 (56.2\%) \\
\hline
\end{tabular}

ML, low grade MALT lymphoma; DLBCL, diffuse large B-cell lymphoma; $\mathrm{ML}+\mathrm{DLBCL}$, high grade MALT Iymphoma; NA, not applicable. a Superficial: from mucosa to submucosa; 'Deep: from mucosa to muscle or beyond. 


\section{Tissue microarray}

Fifty-seven out of 62 surgically resected specimens were used to manufacture the tissue microarray (TMA) slides for FISH. Core tissues (2 mm diameter) were taken from formalin-fixed paraffin embedded blocks (donor blocks) and arranged in a new recipient paraffin block using a trephine apparatus (Superbiochips Laboratories, Seoul, Korea). Lymph node or tonsil specimens showing reactive hyperplasia were also included in the array blocks as a control.

\section{Fluorescence in situ hybridization}

FISH analysis was used to investigate genetic aberrations such as MALT1 rearrangements and numerical aberrations of chromosomes 3 and 18 in 76 primary gastric lymphomas. Two-color interphase FISH for MALT1 rearrangements and one-color for numerical aberrations were done.

Two-color interphase FISH for the detection of MALT1 translocation was performed on sections from TMA and 19 paraffin blocks, as previously described. ${ }^{23}$ Briefly, 4 - $\mu$ m-thick sections were deparaffinized, dehydrated, immersed in $0.2 \mathrm{~N} \mathrm{HCl}$, boiled in a microwave in citrate buffer $(\mathrm{pH}$ 6.0), and incubated in $1 \mathrm{M}$ $\mathrm{NaSCN}$ for $35 \mathrm{~min}$ at $80^{\circ} \mathrm{C}$. Sections were then immersed in pepsin solution, and the tissues were fixed in $10 \%$ neutral-buffered formalin. The probe mixture was applied to the slides, which were then incubated in a humidified atmosphere with Hybrite ${ }^{\mathrm{TM}}$ (Vysis, Downers groove, IL, USA) at $73^{\circ} \mathrm{C}$ for $5 \mathrm{~min}$ to simultaneously denature the probe and target DNA and subsequently at 37 ${ }^{\circ} \mathrm{C}$ for $19 \mathrm{~h}$ for hybridization. The slides were then immersed in $0.4 \times \mathrm{SSC} / 0.3 \% \mathrm{NP}-40$ for $2 \mathrm{~min}$ at room temperature, followed by $2 \times \mathrm{SSC} / 0.1 \% \mathrm{NP}-40$ for $5 \mathrm{~min}$ at $73^{\circ} \mathrm{C}$. The nuclei were counterstained with 4,6-diamidino-2-phenylindole (DAPI) and anti-fade compound (p-phenylenediamine). FISH signals for each locus-specific FISH probe were assessed under an Olympus BX51TRF microscope (Olympus, Japan) equipped with a triplepass filter (DAPI/Green/Orange; Vysis).

To recognize the specific type of MALT1 translocation, FISH analysis was performed in two steps. The first step was to detect any MALT1 translocation using LSI MALT1 dual color breakapart probe (Vysis). Interphase nuclei of normal cells showed two yellow fusion signals (red+green). Rearrangement was defined as any splitting, red and green signal on per nuclei. To clarify the specific counterpart of MALT1 translocation, two fusion translocation probes were used in second step FISH. LSI API2/MALT1 dual color, dual fusion probe (Vysis) to detect $\mathrm{t}(11 ; 18)$ (q21;q21)
API2-MALT1 translocation and LSI IgH/MALT1 dual color, dual fusion probe (Vysis) to detect $\mathrm{t}(14 ; 18)$ (q32; 21$)$ IgH-MALT1 translocation. Interphase nuclei of normal cells showed two green signals for API2 or IgH and two red signals for MALT1. The presence of translocation produced any one yellow fusion signals per nuclei.

To assess numerical aberrations, one color FISH using the centromeric repetitive $\alpha$-satellite DNA probes specific for chromosomes 3 and 18 (Oncor, Gaithersburg, MD, USA) was performed in 76 samples. Interphase nuclei of normal cells showed two red signals showing two copies of chromosomes. Numerical gains of chromosomes such as trisomy or polysomy were defined as increased red signals on per nuclei.

FISH signals were counted by previously described guidelines in the literature to reduce false positives or false negatives. ${ }^{24}$ These guidelines are as follows: 1) only 'intact' (=spherical), non-overlapping nuclei with a clear counterstain were counted; 2) nuclei with paired spots (split spots) were not counted; 3) signals within one nucleus should have more or less the same size and intensity (thus excluding non-specific signals such as minor binding sites); and 4) parallel-cut sections stained with HE were evaluated simultaneously to identify cell types and tissue areas. ${ }^{24}$ In addition, on at least 100 nuclei per hybridized paraffin section, the number of FISH signals were counted. The cutoff levels for each probe were the mean percentage of cells with false positive signals plus 3 standard deviations, which were determined by analyzing 3 reactive tonsils included in a TMA block as a normal control. ${ }^{5}$ Cases showing poor FISH signals were repeatedly examined or substitutively examined by available another samples of same patient. Unanalyzable cases having extremely poor FISH signals or lacking enough tumor cells for interpretation were excluded.

\section{Statistical analysis}

The correlations between clinicopathologic parameters and genetic rearrangements were assessed by Fisher's exact test after transformation into categorical values. Overall survival (OS) was measured from the date of diagnosis to the date of death or the last follow-up visit. Progression-free survival (PFS) was calculated from the date of diagnosis to the date of disease progression, relapse, death, or the last follow-up visit. The survival analysis was performed by the Kaplan and Meier method, and the results were compared by log-rank test. Two-sided p-values $<0.05$ were considered to be statistically significant. Statistical analysis was performed using SPSS for Windows, release 12.0 (SPSS, Chicago, IL, USA). 


\section{RESULTS}

\section{Clinical features of primary gastric lymphoma patients}

The clinical characteristics of 76 primary gastric lymphoma patients were summarized in Table 1. Of 76 cases, 40 (53\%) belonged to low grade MALT lymphomas, $4(5 \%)$ to high grade MALT lymphomas, and the remaining 32 (42\%) to DLBCLs. High grade MALT lymphomas were similar to low grade MALT lymphomas in most clinical characteristics excluding invasion depth. DLBCLs showed the more advanced features in clinicopathologic parameters such as lymph node involvement, stage and survival rate.
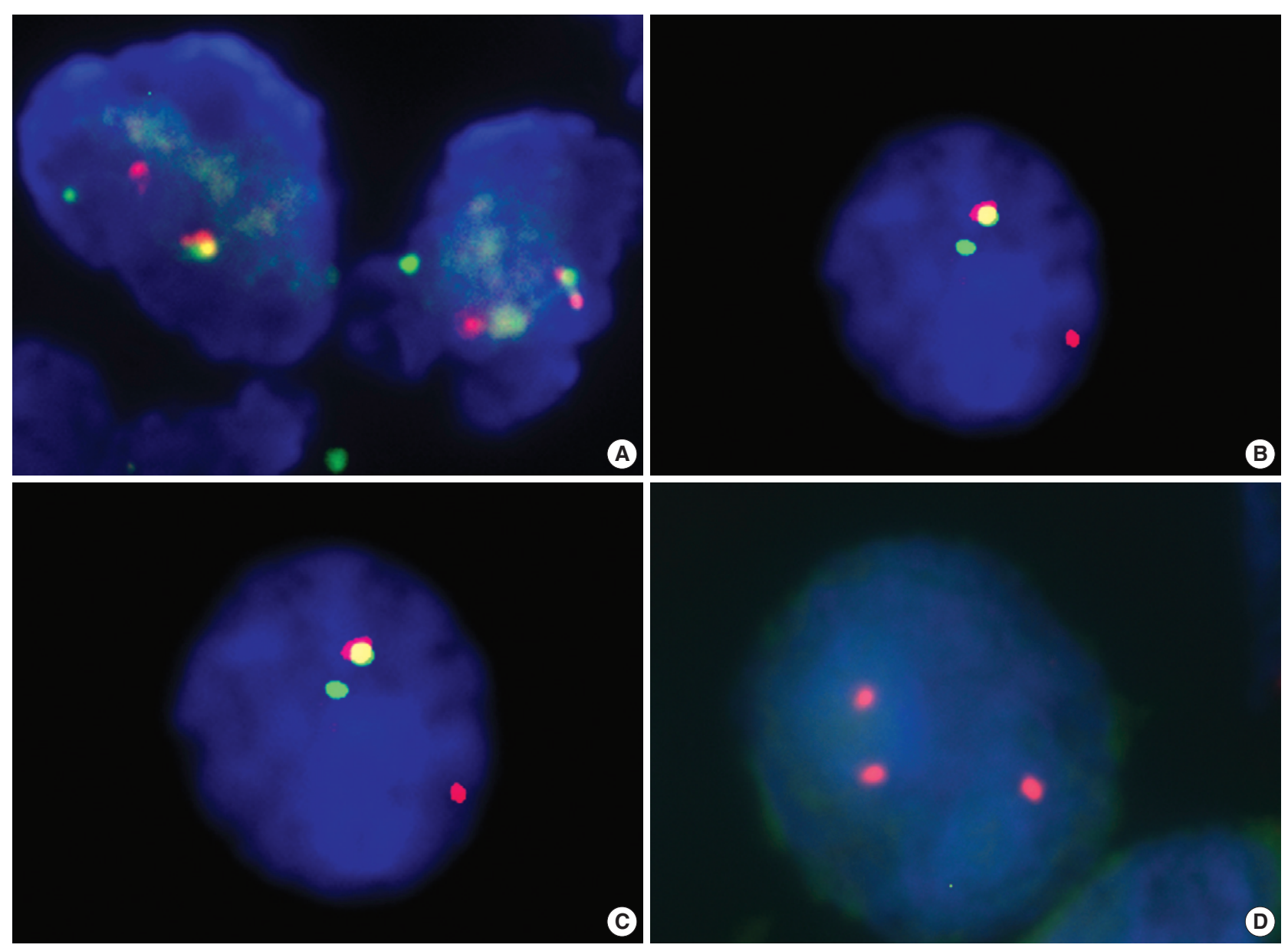

Fig. 1. FISH detection of API2-MALT1 translocation, trisomy 3 and 18 in gastric lymphomas. (A) Green signal represents API2 and red signal MALT1 gene. Yellow fusion signals (red+green) were detected in a t(11;18)-positive case of gastric MALT Iymphoma using dual color dual fusion translocation probe. (B) Separated signals, which consisted of one green (telomeric to MALT1) and red (centromeric to MALT1) signal, were shown in a t(11;18)-positive case of DLBCL using MALT1 dual color break apart rearrangement probe. (C, D) Red signals represent centromeric regions of chromosome 3 (C) or 18 (D). Three red signals were shown in trisomy 3 or 18 of gastric MALT lymphomas, respectively.

\section{Incidence of chromosomal aberrations in primary gastric lymphomas}

In FISH analysis using break apart probe, MALT1 rearrangement was noted in four out of 76 cases. In second step analysis using fusion probe, the $\mathrm{t}(11 ; 18)$ API2-MALT1 translocation was demonstrated in all four cases (Fig. 1A, B). Three cases were low grade MALT lymphomas (7.5\% in low grade MALT lymphoma) and one was DLBCL as shown in Table 2. IgH-MALT1 translocation was not demonstrated.

Numerical aberrations involving chromosome 3 or 18 were all trisomies. Trisomy 3 was observed in seven low grade MALT lymphomas and in one DLBCL (Table 2, Fig. 1C). Of the 11 tumors with trisomy 18, 5 were low grade MALT lymphomas, 2 were high grade MALT lymphomas, and 4 were DLBCLs (Table

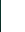


2, Fig. 1D). Overall, 15 of 76 cases (20\%) showed trisomy 3, 18, or both.

Specially, two out of 4 high grade MALT lymphomas showed trisomy 18 (50\%), and numerical gains of chromosome 18 were detected only in DLBCL component of high grade MALT lymphoma showing large cell features, not in low-grade MALT lymphoma component.

In general, genetic aberrations in primary gastric lymphomas, chromosomal rearrangement of MALT 1 and numerical aberrations of chromosome 3 or 18 were observed in mutually exclusive fashion (Table 3). In other words, numerical chromosomal aberration was not detected in $\mathrm{t}(11 ; 18)$ API2-MALT1 translocation-positive cases.

Table 2. Incidence of $\mathrm{t}(11 ; 18), \mathrm{t}(14 ; 18)$, trisomy 3 and 18 in primary gastric lymphomas

\begin{tabular}{lllcll}
\hline & & $t(11 ; 18)$ & $t(14 ; 18)$ & Trisomy 3 & Trisomy 18 \\
\hline ML & $(n=40)$ & $3(7.5 \%)$ & 0 & $7(17.5 \%)$ & $5(12.5 \%)$ \\
ML+DLBCL & $(n=4)$ & $0(0 \%)$ & 0 & 0 & $2(50 \%)$ \\
DLBCL & $(n=32)$ & $1(3 \%)$ & 0 & $1(3 \%)$ & $4(12.5 \%)$ \\
Total & $(n=76)$ & $4(5 \%)$ & 0 & $8(11 \%)$ & $11(14 \%)$ \\
\hline
\end{tabular}

ML, low grade MALT Iymphoma; DLBCL, diffuse large B-cell lymphoma; $\mathrm{ML}+\mathrm{DLBCL}$, high grade MALT lymphoma.

Table 3. Overview of genetic aberrations in primary gastric lymphomas

\begin{tabular}{rcccc}
\hline Case & Grade & Translocation & Chromosome 3 & Chromosome 18 \\
\hline 4 & $\mathrm{ML}$ & $\mathrm{N}$ & $\mathrm{N}$ & Trisomy 18 \\
8 & $\mathrm{ML}$ & $\mathrm{N}$ & Trisomy 3 & Trisomy 18 \\
12 & $\mathrm{ML}$ & $\mathrm{N}$ & $\mathrm{N}$ & Trisomy 18 \\
15 & $\mathrm{ML}$ & $\mathrm{N}$ & Trisomy 3 & $\mathrm{N}$ \\
16 & $\mathrm{ML}$ & $\mathrm{N}$ & Trisomy 3 & Trisomy 18 \\
23 & $\mathrm{ML}$ & $\mathrm{N}$ & Trisomy 3 & $\mathrm{N}$ \\
30 & $\mathrm{ML}$ & $\mathrm{t}(11 ; 18)$ & $\mathrm{N}$ & $\mathrm{N}$ \\
32 & $\mathrm{ML}$ & $\mathrm{t}(11 ; 18)$ & $\mathrm{N}$ & $\mathrm{N}$ \\
34 & $\mathrm{ML}$ & $\mathrm{t}(11 ; 18)$ & $\mathrm{N}$ & $\mathrm{N}$ \\
36 & $\mathrm{ML}$ & $\mathrm{N}$ & Trisomy 3 & Trisomy 18 \\
37 & $\mathrm{ML}$ & $\mathrm{N}$ & Trisomy 3 & $\mathrm{N}$ \\
39 & $\mathrm{ML}$ & $\mathrm{N}$ & Trisomy 3 & $\mathrm{N}$ \\
41 & $\mathrm{ML}+\mathrm{DLBCL}$ & $\mathrm{N}$ & $\mathrm{N}$ & Trisomy 18 \\
42 & $\mathrm{ML}+\mathrm{DLBCL}$ & $\mathrm{N}$ & $\mathrm{N}$ & Trisomy 18 \\
46 & $\mathrm{DLBCL}$ & $\mathrm{N}$ & $\mathrm{N}$ & Trisomy 18 \\
47 & $\mathrm{DLBCL}$ & $\mathrm{N}$ & $\mathrm{N}$ & Trisomy 18 \\
50 & $\mathrm{DLBCL}$ & $\mathrm{N}$ & Trisomy 3 & Trisomy 18 \\
65 & $\mathrm{DLBCL}$ & $\mathrm{N}$ & $\mathrm{N}$ & Trisomy 18 \\
67 & $\mathrm{DLBCL}$ & $\mathrm{t}(11 ; 18)$ & $\mathrm{NA}$ & $\mathrm{N}$ \\
\hline
\end{tabular}

ML, low grade MALT lymphoma; DLBCL, diffuse large B-cell lymphoma; $\mathrm{ML}+\mathrm{DLBCL}$, high grade MALT lymphoma; N, normal (no genetic aberrations found); NA, not applicable.

\section{Relationship between chromosomal aberrations and clinicopathologic features in gastric low grade MALT lymphomas}

The correlations between MALT1 translocation between main clinicopatholgic parameters in gastric low grade MALT lymphomas were shown in Table 4. API2-MALT1 translocation-positive cases were associated with more advanced stage, deeper invasion, regional lymph node involvement and disease progression or relapse, although number of positive cases is too limited to generalize it. Other clinicopathologic parameters, including age, H. pylori status, response to eradication therapy, and bone marrow involvement, did not show any differences between translocation-positive and negative group.

There were no statistically significant differences in clinicopathologic parameters between trisomy-positive and negative groups.

\section{Prognostic correlation of chromosomal aberrations in gastric low grade MALT lymphomas}

The follow-up period was ranged from 4 to 159 months (71.2 \pm 38.7 and median 61.2 months). All low grade MALT lymphoma patients survived with OS rate, $100 \%$. The PFS rate after 3 -years

Table 4. Correlation between $\mathrm{t}(11 ; 18)(\mathrm{q} 21 ; \mathrm{q} 21)$ API2-MALT1 translocation and main clinicopathologic features in low grade MALT lymphomas

\begin{tabular}{|c|c|c|c|}
\hline & t(11;18)-positive & $\mathrm{t}(11 ; 18)$-negative & $\mathrm{p}$ \\
\hline \multicolumn{4}{|l|}{ Age } \\
\hline$\leq 60$ years & 3 & 30 & 1.0 \\
\hline$>60$ years & 0 & 6 & \\
\hline \multicolumn{4}{|l|}{ Depth of invasion } \\
\hline Superficial & 0 & 19 & 0.033 \\
\hline Deep & 3 & 7 & \\
\hline \multicolumn{4}{|l|}{ Clinical stage } \\
\hline 1 & 1 & 33 & 0.038 \\
\hline II or higher & 2 & 3 & \\
\hline \multicolumn{4}{|l|}{ H. pylori status } \\
\hline Positive & 1 & 13 & 0.596 \\
\hline Negative & 2 & 16 & \\
\hline \multicolumn{4}{|l|}{ Response to eradication } \\
\hline Complete remission (CR) & 0 & 10 & 0.167 \\
\hline Non-CR & 1 & 1 & \\
\hline \multicolumn{4}{|l|}{ Bone marrow involvement } \\
\hline Yes & 1 & 2 & 0.489 \\
\hline No & 2 & 11 & \\
\hline \multicolumn{4}{|l|}{ Lymph node involvement } \\
\hline Positive & 2 & 4 & 0.062 \\
\hline Negative & 1 & 30 & \\
\hline \multicolumn{4}{|l|}{ Progression or relapse } \\
\hline Yes & 2 & 1 & 0.018 \\
\hline No & 1 & 28 & \\
\hline
\end{tabular}


was $91 \%$. Three cases showed progression $(n=2)$ or relapse $(n=1)$. Two out of these 3 cases showed MALT1 rearrangement. Cases with API2-MALT1 translocation showed worse PFS ( $\mathrm{p}=0.00)$ by the Kaplan and Meier method with log-rank test, although number of positive cases is too small to generalize the results. Numerical aberrations were not correlated with PFS (trisomy 3, $\mathrm{p}=0.39$; trismoy $18, \mathrm{p}=0.56$ ).

\section{DISCUSSION}

In the present study, the $\mathrm{t}(11 ; 18)(\mathrm{q} 21 ; \mathrm{q} 21)$ API2-MALT1 translocation in gastric low grade MALT lymphomas was noted in 3 out of 40 cases $(7.5 \%)$. In previous studies, the reported incidence of $\mathrm{t}(11 ; 18)$ harboring API2-MALT1 fusion was so variable, ranged from $5 \%$ to $48 \%$. $^{4-16}$ In terms of geographic variation, the reported incidence of $\mathrm{t}(11 ; 18)$ in gastric low grade MALT lymphomas was $15-48 \%($ mean $=28 \%)$ in Europe, ${ }^{4-10} 11.6-21 \%$ (mean $=15.4 \%$ ) in Japan, ${ }^{11-14.16}$ and $5 \%$ in North America. ${ }^{15}$ These data suggest that the incidence of translocation involving MALT1 may be different according to geographic area, and Asian population may have the lower incidence than European population. In this study on Korean population, the incidence of MALT 1 translocation (7.5\%) is lower than the reported incidences of Europe, and a little lower than the reported incidences of Japan. These results are in agreement with geographic variation and lower incidence in Asian population in previous reports.

There are conflicting reports about whether the incidence of translocation in gastric low grade MALT lymphomas was really different according to the geographical locations in spite of bias in case selection, sample size and technical problem of previous studies. ${ }^{15,16}$ In a recent, large scale study on Japanese population by Nakamura et al. ${ }^{16}$ the incidence of translocation involving MALT1 in Japanese population (21\%) was similar to that (15-24\%) of other previous studies on European populations comprising more than 60 gastric cases, excluding the studies of small sample size. In this respect, small sample size of our study $(\mathrm{n}=40)$ might cause this discrepancy. However, the influence of sample size is unclear in that the criterion of selection ( $\mathrm{n}>60)$ used in study by Nakamura et al. is somewhat arbitrary and previous studies showed the regular trend regarding geographic variation irrespective of sample size.

As another cause of underdetection, efficacy of detection method could be considered. In this study, FISH analysis only was used as a detection method. Some studies used reverse transcriptasepolymerase chain reaction (RT-PCR) as a second method for detection of translocation when FISH signal was poor or inappro- priate for investigation due to containment of a little portion of MALT lymphoma within paraffin block or incomplete fixation of specimens. ${ }^{4,7,16}$ In our study, three cases showing poor FISH signal were included and one case was finally unanalyzable in spite of repeated examination, which might cause underdetection. However, in some study using FISH only as a detection method, the reported incidence is not so different to that of the studies using dual methods. ${ }^{5}$ In addition, RT-PCR and FISH have no significant difference in sensitivity or specificity in previous studies, which investigated the translocation twice on same specimen by dual methods. ${ }^{4,7.8}$ Therefore FISH only method in our study might not cause a serious bias in incidence of translocation.

Consequently, the result of this study may be an additional report that supports geographic variation in incidence of $t(11 ; 18)$ (q21;q21) API2-MALT1 translocation in gastric lymphomas although this study has some limitation to be generalized due to small sample size and restricted detection method.

In our study, the trends suggesting local aggressiveness and advanced clinical situations of translocation-positive gastric MALT lymphoma were shown, in consistency with those of several previous studies, ${ }^{10,14,17,25}$ although the number of translocation-positive cases was too small to generalize it. In addition to the small number of positive cases, heterogeneity of tissue obtaining methods such as gastrectomy and endoscopic biopsy could influence the result of statistical analysis and act as a cause of bias in evaluating clinicopathologic parameters such as lymph node involvement, depth of invasion and stage. Radiological evaluation in biopsy cases might underestimate or overestimate the actual severity of these parameters than histologic examination in gastrectomy cases.

One case showing $\mathrm{t}(11 ; 18)$ API2-MALT1 translocation was noted among 32 cases of DLBCL (3.1\%). This result is consistent with those of previous studies, which reported that $\mathrm{t}(11 ; 18)$ API2-MALT1 translocation has been rarely observed in DLBCL., ${ }^{3,6}$

Another translocation involving MALT1, t(14;18)(q32;q21) IgH-MALT1 translocation, was not demonstrated. This result corresponds with that of the earlier studies, showing the rarity of $\mathrm{t}(14 ; 18)(\mathrm{q} 32 ; \mathrm{q} 21) \operatorname{IgH}-M A L T 1$ translocation in gastric MALT lymphomas. ${ }^{7,815}$ Recent large scale study showed t(14;18) IgHMALT1 was observed mainly in MALT lymphoma of extra-gastrointestinal site such as salivary gland, ocular adnexa and lung, suggestive of anatomic site specificity of translocations in MALT lymphoma. ${ }^{15}$

Numerical aberrations of chromosomes 3 or 18 was observed in translocation-negative cases in mutually exclusive fashion with $\mathrm{t}(11 ; 18)$ API2-MALT1 translocation, in agreement with previous study. ${ }^{4}$ This result suggests that numerical aberration and $\mathrm{t}(11$; 
Table 5. Clinical characteristics of three progressed or recurrent cases of low grade MALT Iymphoma

\begin{tabular}{|c|c|c|c|c|c|c|c|c|c|c|}
\hline Case & Sex/age & Stage & $t(11 ; 18)$ & H. pylori & $\begin{array}{l}\text { Eradi- } \\
\text { cation }\end{array}$ & Tx & $\begin{array}{c}\text { Progression } \\
\text { or relapse }\end{array}$ & $\begin{array}{l}\text { Status } \\
\text { after Tx }\end{array}$ & Survival & $\begin{array}{c}\mathrm{F} / \mathrm{U} \\
\text { (mon) }\end{array}$ \\
\hline 25 & $M / 65$ & I & Neg & Neg & Fail & $1^{\circ} \mathrm{CT}, 2^{\circ} \mathrm{RT}$ & Relapse & CR & Yes & 31 \\
\hline 30 & M/52 & IV & Pos & Neg & Not done & F/U loss & Progression & Unknown & Yes & loss \\
\hline 34 & $\mathrm{M} / 49$ & 1 & Pos & Pos & Fail & TG & Progression & CR & Yes & 44 \\
\hline
\end{tabular}

Neg, negative; Pos, positive; TG, total gastrectomy; F/U, follow up; Tx, treatment; CT, chemotherapy; RT, radiotherapy; mon, months.

18) translocation represents two different biologic mechanisms related to the pathogenesis of MALT lyphomas. ${ }^{4,26,27}$ Specially, trisomy 18 was detected within DLBCL component in 2 out of 4 high grade MALT lymphoma cases (50\%). These results are in consistency with previous reports, indicating that chromosomal aneuploidy such as trisomy 3,18 are associated with high grade transformation of low grade MALT lymphoma. ${ }^{4,26}$ Recent studies suggests that gastric MALT lymphomas can be classified into 3 groups according to API2-MALT1 translocation status and response to $H$. pylori eradication therapy; eradication-responders without API2-MALT1, nonresponders without API2-MALT1, and nonresponders with API2-MALT1 14,20.28 In these studies, eradication-nonresponders without API2-MALT1 group was shown to be associated with a greater risk with high grade transformation, more advanced clinical features and variable, numerous genetic alterations excluding API2-MALT1 translocation..$^{14,20,28-30}$ In this respect, trisomy 3 or 18 represents some aspects of variable genetic aberrations of this group, although trisomies are probably part of the abnormalities, cytogenetically detectable at microscopic level.

There have been several reports indicating that $H$. pylori eradication failure was frequent in API2-MALT1 translocation-positive group, as shown in aforementioned three-categorized grouping. ${ }^{10,14}$ In the present study, 1 out of 3 translocation-positive cases failed to eradication therapy. There are some limitations to evaluate the therapeutic responses of conservative treatment; the number of eradication therapy group ( $\mathrm{n}=12)$ was too small to analyze the results properly and the study population mainly consisted of gastrectomy specimen $(n=26)$, which was performed before conservative management has been established.

Overall survival of low grade MALT lymphoma patients was very good for long-term clinical observation. All patients survived, and only three progressed or recurrent cases were observed (Table 5). One progressed case was cured by total gastrectomy after eradication failure, and another progressed case was lost during follow-up but recognized as alive until now. One recurrent case, with initial bone marrow involvement, was treated by chemotherapy after eradication failure, and then radiation therapy after relapse, is still alive with no evidence of disease. Two of these three cases had API2-MALT1 fusion transcripts. These results were consistent with long term clinical outcome results of a recent study, suggestive of good prognosis even in no treated API2-MALT1 fusion-positive cases ${ }^{28}$ In addition, the aforementioned fact that majority of this study population underwent curative operation may be related to the good prognosis of this study population.

The prognostic correlation of numerical aberrations was not revealed in this study, but the possible association of $t(11 ; 18)$ API2-MALT1 with adverse clinical behavior such as progression or relapse was suggested, but rarity of positive cases makes it difficult to generalize it.

In conclusion, our study showed that the $\mathrm{t}(11 ; 18)$ harboring API2-MALT1 fusion is not quite frequent in gastric low grade MALT lymphoma of Korean populations, which suggests geographic variation of the incidence of $t(11 ; 18)$ involving API2$M A L T 1$ and relatively lower incidence in Korean population. The $\mathrm{t}(11 ; 18)$ API2-MALT1 was associated with local aggressiveness and progression or relapse of low grade MALT lymphomas. Trisomy 18 was frequently observed in DLBCL component of high grade MALT lymphomas, indicating the association with high grade transformation. Long-term clinical follow-up confirms very good prognosis of low grade MALT lymphoma cases after the successful treatments for the progressed or recurrent diseases.

\section{REFERENCES}

1. Stolte M, Bayerdorffer E, Morgner A, et al. Helicobacter and gastric MALT lymphoma. Gut 2002; 50 (Suppl 3): III19-24.

2. Du MQ, Atherton JC. Molecular subtyping of gastric MALT lymphomas: implications for prognosis and management. Gut 2006; 55 : 886-93.

3. Remstein ED, James CD, Kurtin PJ. Incidence and subtype specificity of API2-MALT1 fusion translocations in extranodal, nodal, and splenic marginal zone lymphomas. Am J Pathol 2000; 156: 1183-8.

4. Schreuder MI, Hoeve MA, Hebeda KM, et al. Mutual exclusion of $\mathrm{t}(11 ; 18)(\mathrm{q} 21 ; \mathrm{q} 21)$ and numerical chromosomal aberrations in the development of different types of primary gastric lymphomas. Br J Ha- 
ematol 2003; 123: 590-9.

5. Murga Penas EM, Hinz K, Roser K, et al. Translocations t(11;18)(q21;q21) and $\mathrm{t}(14 ; 18)(\mathrm{q} 32 ; \mathrm{q} 21)$ are the main chromosomal abnormalities involving MLT/MALT1 in MALT lymphomas. Leukemia 2003; 17: 2225-9.

6. Baens M, Maes B, Steyls A, Geboes K, Marynen P, De Wolf-Peeters C. The product of the $\mathrm{t}(11 ; 18)$, an API2-MLT fusion, marks nearly half of gastric MALT type lymphomas without large cell proliferation. Am J Pathol 2000; 156: 1433-9.

7. Streubel B, Simonitsch-Klupp I, Mullauer L, et al. Variable frequencies of MALT lymphoma-associated genetic aberrations in MALT lymphomas of different sites. Leukemia 2004; 18: 1722-6.

8. Ye H, Gong L, Liu H, et al. MALT lymphoma with $\mathrm{t}(14 ; 18)(\mathrm{q} 32 ; \mathrm{q} 21) /$ IGH-MALT1 is characterized by strong cytoplasmic MALT1 and BCL10 expression. J Pathol 2005; 205: 293-301.

9. Wundisch T, Thiede C, Morgner A, et al. Long-term follow-up of gastric MALT lymphoma after Helicobacter pylori eradication. J Clin Oncol 2005; 23: 8018-24.

10. Liu H, Ye H, Ruskone-Fourmestraux A, et al. $\mathrm{T}(11 ; 18)$ is a marker for all stage gastric MALT lymphomas that will not respond to $H$. pylori eradication. Gastroenterology 2002; 122: 1286-94.

11. Inagaki $\mathrm{H}$, Okabe M, Seto M, Nakamura S, Ueda R, Eimoto T. API2MALT1 fusion transcripts involved in mucosa-associated lymphoid tissue lymphoma: multiplex RT-PCR detection using formalin-fixed paraffin-embedded specimens. Am J Pathol 2001; 158: 699-706.

12. Nakamura S, Matsumoto T, Nakamura S, et al. Chromosomal translocation $\mathrm{t}(11 ; 18)(\mathrm{q} 21 ; \mathrm{q} 21)$ in gastrointestinal mucosa associated lymphoid tissue lymphoma. J Clin Pathol 2003; 56: 36-42.

13. Yonezumi M, Suzuki R, Suzuki H, et al. Detection of AP12-MALT1 chimaeric gene in extranodal and nodal marginal zone B-cell lymphoma by reverse transcription polymerase chain reaction (PCR) and genomic long and accurate PCR analyses. Br J Haematol 2001; 115: 588-94.

14. Inagaki H, Nakamura T, Li C, et al. Gastric MALT lymphomas are divided into three groups based on responsiveness to Helicobacter pylori eradication and detection of API2-MALT1 fusion. Am J Surg Pathol 2004; 28: 1560-7.

15. Remstein ED, Dogan A, Einerson RR, et al. The incidence and anatomic site specificity of chromosomal translocations in primary extranodal marginal zone B-cell lymphoma of mucosa-associated lymphoid tissue (MALT lymphoma) in North America. Am J Surg Pathol 2006; 30:1546-53.

16. Nakamura S, Ye H, Bacon CM, et al. Clinical impact of genetic aberrations in gastric MALT lymphoma: a comprehensive analysis using interphase fluorescence in situ hybridisation. Gut 2007; 56: 1358-63.

17. Liu H, Ye H, Dogan A, et al. T(11;18)(q21;q21) is associated with advanced mucosa-associated lymphoid tissue lymphoma that express- es nuclear BCL10. Blood 2001; 98: 1182-7.

18. Remstein ED, Kurtin PJ, James CD, Wang XY, Meyer RG, Dewald GW. Mucosa-associated lymphoid tissue lymphomas with $t(11 ; 18)$ (q21;q21) and mucosa-associated lymphoid tissue lymphomas with aneuploidy develop along different pathogenetic pathways. Am J Pathol 2002; 161: 63-71.

19. Taji S, Nomura K, Matsumoto Y, et al. Trisomy 3 may predict a poor response of gastric MALT lymphoma to Helicobacter pylori eradication therapy. World J Gastroenterol 2005; 11: 89-93.

20. Inagaki H. Mucosa-associated lymphoid tissue lymphoma: molecular pathogenesis and clinicopathological significance. Pathol Int 2007; 57: 474-84.

21. Jaffe ES, Harris NL, Stein H, et al. World Health Organization Classification of tumours. Pathology and Genetics of Tumours of the Hematopoietic and Lymphoid tissues. Lyon, France: IARC Press, 2001; 157-60.

22. Isaacson PG. Gastrointestinal lymphoma. Hum Pathol 1994; 25: 1020-9.

23. Ye H, Liu H, Attygalle A, et al. Variable frequencies of $\mathrm{t}(11 ; 18)$ (q21; q21) in MALT lymphomas of different sites: significant association with CagA strains of $H$ pylori in gastric MALT lymphoma. Blood 2003; 102: 1012-8.

24. Hoeve MA, Gisbertz IA, Schouten HC, et al. Gastric low-grade MALT lymphoma, high-grade MALT lymphoma and diffuse large B cell lymphoma show different frequencies of trisomy. Leukemia 1999; 13: 799-807.

25. Ye H, Liu H, Raderer M, et al. High incidence of $\mathrm{t}(11 ; 18)(\mathrm{q} 21 ; \mathrm{q} 21)$ in Helicobacter pylori-negative gastric MALT lymphoma. Blood 2003; 101: 2547-50.

26. Tai YC, Tan JA, Peh SC. 18q21 Rearrangement and trisomy 3 in extranodal B-cell lymphomas: a study using a fluorescent in situ hybridisation technique. Virchows Arch 2004; 445: 506-14.

27. Starostik P, Patzner J, Greiner A, et al. Gastric marginal zone B-cell lymphomas of MALT type develop along 2 distinct pathogenetic pathways. Blood 2002; 99: 3-9.

28. Nakamura T, Seto M, Tajika M, et al. Clinical features and prognosis of gastric MALT lymphoma with special reference to responsiveness to H. pylori eradication and API2-MALT1 status. Am J Gastroenterol 2008; 103: 62-70.

29. Zhou Y, Ye H, Martin-Subero JI, et al. Distinct comparative genomic hybridisation profiles in gastric mucosa-associated lymphoid tissue lymphomas with and without t(11;18)(q21;q21). Br J Haematol 2006; 133: 35-42.

30. Fukuhara N, Nakamura T, Nakagawa M, et al. Chromosomal imbalances are associated with outcome of Helicobacter pylori eradication in $\mathrm{t}(11 ; 18)(\mathrm{q} 21 ; \mathrm{q} 21)$ negative gastric mucosa-associated lymphoid tissue lymphomas. Genes Chromosomes Cancer 2007; 46: 784-90. 